\title{
A microelectrode-based sensor for measuring operando active species concentrations in redox flow cells
}

\author{
Bertrand J. Neyhouse, ${ }^{1}$ Kevin M. Tenny, ${ }^{1}$ Yet-Ming Chiang, ${ }^{2}$ and Fikile R. Brushett ${ }^{1, *}$ \\ ${ }^{1}$ Department of Chemical Engineering, Massachusetts Institute of Technology, Cambridge, MA 02139 \\ ${ }^{2}$ Department of Materials Science and Engineering, Massachusetts Institute of Technology, Cambridge, MA 02139 \\ *Corresponding author: brushett@mit.edu
}

\begin{abstract}
The assessment of candidate materials for redox flow batteries requires effective diagnostic techniques for monitoring the evolution of electrolyte state of charge and state of health to interrogate time-dependent changes in system behavior. Further, such tools can be applied in practical embodiments to inform maintenance schedules and optimize energy utilization. In this work, we develop and test a flow-through, microelectrode-based electrochemical sensor to continuously measure active species concentrations in redox flow cells. A gold microelectrode (working electrode) and platinum wire (pseudo-reference electrode) are sealed into a stainlesssteel fitting (counter electrode), and three-electrode electroanalytical techniques (i.e., voltammetry, chronoamperometry) are performed to correlate steady-state current to concentration. To validate transport and thermodynamics that govern the sensing mechanism, we combine multiphysics simulation with ex situ experimental testing, confirming the device is capable of accurately determining individual species concentrations. We then evaluate the microelectrode sensor in a symmetric redox flow cell, demonstrating the utility of this approach for measuring operando concentrations, and discuss additional considerations for successful implementation (e.g., measurement protocol, material selection, flow cell design). Assembled from commercially available, off-the-shelf components, the sensor can be readily adopted by research laboratories and integrated into existing experimental workflows, making it a promising tool for studying novel flow battery materials.
\end{abstract}


Keywords: Redox flow batteries, flow cells, electrochemical sensors, microelectrodes, organic redox couples, state of charge, state of health 


\section{Introduction}

Redox flow batteries (RFBs) hold promise as an electrochemical energy storage platform that may enable integration of intermittent renewable resources and bolster existing grid infrastructure, but further cost reductions are needed for widespread deployment. ${ }^{1,2}$ To this end, a range of multidisciplinary science and engineering approaches have advanced different system components, including electrolytes (i.e., redox species, supporting salts, solvents), electrodes, flow fields, and membranes/separators, with the ultimate goal of enabling lower-cost and higher-performing systems. ${ }^{3,4}$ As the community continues to explore the frontiers of materials discovery and integrate new elements into this technology, robust methodologies are needed to assess the performance of these emerging materials in formats that approximate practical embodiments. Of particular importance is the durational stability, as the charge storage capacity and energy efficiency can fade over time due to compositional changes in the electrolytes (e.g., crossover, active species decomposition) and wear of wetted components. The degradation of individual components dictates system maintenance schedules and operating expenses, as routine repairs and replacements are feasible but adversely impact profitability over the service life of the battery. 5,6 However, performance losses in such complex systems are often rooted in a multitude of confounding factors, such as electrode and membrane degradation, crossover, solvent evaporation, molecular decay, which are difficult to decouple experimentally and/or to replicate in isolation. ${ }^{7-}$ ${ }^{10}$ Understanding modes of performance loss requires diagnostic tools that can monitor the RFB throughout its operating lifetime. ${ }^{11}$ Such insights into the state of the system would allow researchers to interrogate mechanisms of component failure and operators to improve asset utilization and maintenance planning. 
The condition of the electrolyte is characterized by either its state of charge (SOC), which reflects the fraction of the total species concentration in the charged form, or state of health ( $\mathrm{SOH}$ ), which reflects the fraction of species available for electrochemical reaction compared against a reference concentration, typically defined as the concentration at the start of life. ${ }^{11}$ There are numerous experimental methods that can be used to track SOC and SOH in RFBs, which vary depending on the electrolyte chemistry and the desired analytical information. Spectroscopic techniques, including spectrophotometry, ${ }^{12,13}$ nuclear magnetic resonance spectroscopy, ${ }^{14-16}$ electron paramagnetic resonance spectroscopy, ${ }^{14,17,18}$ and infrared spectroscopy, ${ }^{19,20}$ can enable quantitative measurements of the species concentration and, in some cases, elicit chemical information about the stability and decomposition products of different species within the electrolyte, but these typically require specialized hardware and infrastructure to be performed in situ or operando. ${ }^{21}$ In lieu of more comprehensive chemical characterizations of the electrolyte, one can monitor physicochemical (e.g., density, ${ }^{22}$ viscosity ${ }^{23}$ ) and electrochemical descriptors (e.g., conductivity, ${ }^{24,25}$ open-circuit potential ${ }^{26}$ ) that in many instances correlate to electrolyte SOC. For example, in-line electrochemical cells can be used to measure the open circuit potential between the two electrolytes, which can be related to the overall SOC through equilibrium thermodynamic expressions. ${ }^{27-29}$ Similarly, external reference electrodes can be introduced to measure the open circuit potential at a model electrode surface, which captures the equilibrium potential of each electrolyte independently, allowing determination of individual electrolyte SOCs. ${ }^{26,30-32}$ The resultant SOC assessment from these techniques offers a cursory glance into the health of the electrolyte and the balance of charge between the two half-cells. However, these methods only describe the relative electroactive species concentrations, which presents inherent 
limitations in cases where performance decay is related to species crossover and decomposition, as these processes can lead to changes in the total concentrations in each half-cell.

Most methods for monitoring SOC only measure the ratio of species concentrations in different oxidation states; however, the magnitudes of these concentrations are necessary to determine the $\mathrm{SOH}$ and elucidate sources of performance loss (e.g., crossover, species decay, self-discharge). While concentration measurements are often more challenging, electroanalytical techniques are well suited to quantify electroactive species in redox systems. ${ }^{33-35}$ For example, amperometric measurements have been performed on gas diffusion electrodes to measure vanadium (IV) and vanadium (V) concentrations; but despite the robust methodology, the protocol requires specialized equipment to prepare electrodes. ${ }^{36}$ Microelectrode voltammetry has also been demonstrated as a viable method for measuring redox species concentrations and assessing the decay of active materials ex situ in deterministically prepared electrolytes. ${ }^{37}$ Microelectrodes have the distinct advantage of decoupling redox species concentrations, as their small active area enables steady-state voltammetric measurements at reasonably low scan rates (ca. $10 \mathrm{mV} \mathrm{s}^{-1}$ ). Further, the resultant low currents minimize ohmic distortions and capacitive currents, enabling electrochemical measurements in more complex electrolytes, such as highly concentrated or low supporting salt environments. ${ }^{38,39}$ However, typical three-electrode voltammetry experiments are challenging to perform in situ, as cross-contamination through the semi-permeable frit that separates the reference electrode fill solution from the surrounding electrolyte adversely impact s measurement reliability and longevity. Voltammetry is also commonly performed under either quiescent (e.g., cyclic voltammetry (CV)) or controlled hydrodynamic conditions (e.g., rotating disk electrodes), but non-uniform convection in the electrolyte reservoirs and redox flow cell can frustrate operando measurements. Microelectrodes were recently applied to monitor electrolyte 
SOC in RFBs using the ratio of steady state currents obtained from $\mathrm{CV}$, but this implementation fell short of evaluating concentrations, owing to surface fouling and placement of the microelectrode directly in the electrolyte reservoir. ${ }^{40}$ To enable high fidelity concentration measurements, the flow conditions around the electrode need to be uniform and consistent, and species transport must be well understood. Additionally, eliminating fouling necessitates judicious pairing of electrode materials and redox species alongside careful operation and maintenance.

In this work, we describe an in-line, flow-through microelectrode sensor (Figure 1) for use as an operando diagnostic tool to measure redox species concentrations within a flow cell. The device leverages a three-electrode assembly to accurately quantify species concentrations via the steadystate current obtained through voltammetry and chronoamperometry. To provide a stable reference potential, the sensor uses a platinum (Pt) wire pseudo-reference electrode in place of a more standard fritted reference electrode to reduce cross-contamination and associated potential drift. We validate the proposed working principle using multiphysics simulations in an idealized domain and assess the measurement protocol using a model electroactive compound ( $N$-(2-(2methoxyethoxy)ethyl)phenothiazine, MEEPT) ${ }^{41}$ prepared at varying SOCs. Ex situ measurements confirm the current is a linear function of concentration under steady flow conditions, indicating that the respective species concentrations can be determined using an empirical mass transfer coefficient, which is calibrated internally. As a proof-of-concept, we demonstrate the efficacy of this approach for measuring individual species concentrations during potentiodynamic operation by employing the microelectrode sensor in a symmetric redox flow cell containing MEEPT/MEEPT ${ }^{+}$. Importantly, the device is readily assembled from commercial, off-the-shelf materials and can be easily integrated into existing experimental workflows, making it accessible to the research community. 


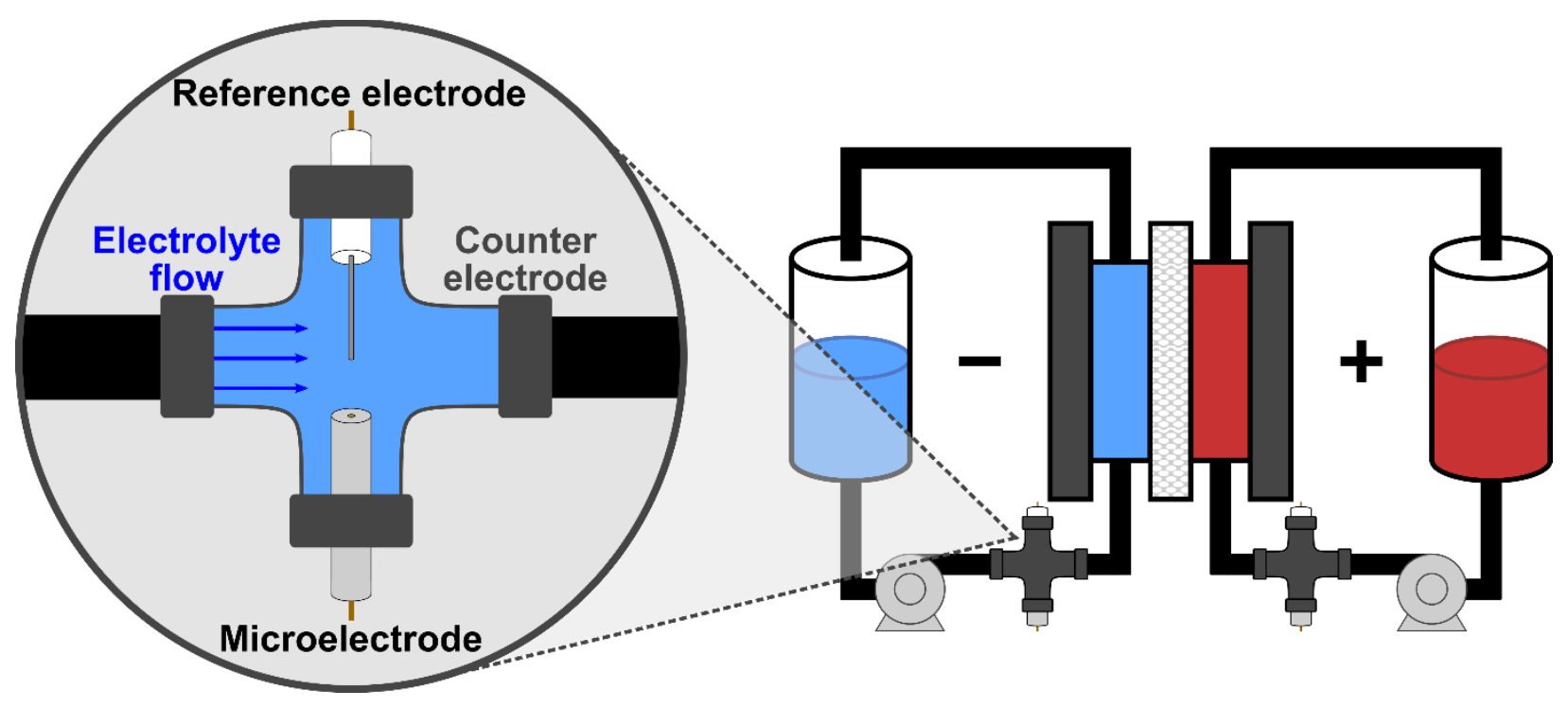

Figure 1. Graphical representation of the in-line, flow-through microelectrode sensor for measuring operando concentrations in RFBs. The device features a microelectrode as the working electrode, a Pt wire as the pseudo-reference electrode, and a stainless steel counter electrode, which also serves as the body of the cell. 


\section{Experimental methods}

All electrochemical experiments were conducted in a supporting electrolyte consisting of 500 $\mathrm{mM}$ tetraethylammonium tetrafluoroborate $\left(\mathrm{TEABF}_{4}\right.$, Gotion, $\left.>99.9 \%\right)$ in propylene carbonate (PC, Gotion, > 99.9\%). This composition was selected because of its wide electrochemical stability window and low volatility. MEEPT (TCI, > 98.0\%) was used as the redox-active species. Oxidized MEEPT (MEEPT-BF 4 ) was prepared by chemical oxidation ${ }^{42}$ via the addition of 1.05 molar equivalents of nitrosonium tetrafluoroborate $\left(\mathrm{NOBF}_{4}\right.$, Alfa Aesar, > 98\%) in dichloromethane (Avantor, 99.9\%), followed by precipitation with diethyl ether (Avantor, ACS reagent grade). The product was then precipitated twice from dichloromethane into diethyl ether to remove impurities

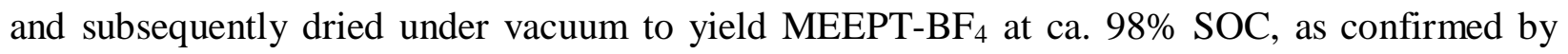
microelectrode voltammetry. All chemicals were used as-received, and electrolyte formulations were prepared a day in advance of use to ensure complete dissolution of solutes. Electrolyte viscosity was measured using a Viscolite V-700 vibrational viscometer probe and the density was calculated from the mass of a $20 \mathrm{~mL}$ solution prepared in a volumetric flask. Prior to use, electrodes were polished on a MicroCloth pad containing an aqueous slurry of $0.05 \mu \mathrm{m}$ alumina powder (Buehler Ltd.), rinsed with deionized water (18.2 M $\Omega$, Milli-Q), wiped with lens paper, rinsed with acetone (VWR, > 99.5\%), and dried with compressed air. An argon-filled glovebox (MBraun Labmaster, $\mathrm{H}_{2} \mathrm{O}<5 \mathrm{ppm}, \mathrm{O}_{2}<1 \mathrm{ppm}$ ) with an ambient temperature of $26^{\circ} \mathrm{C}$ was used for chemical storage, solution preparation, and voltammetry measurements. The flow-through microelectrode sensor and symmetric flow cell cycling experiments were performed on the benchtop with the cell maintained in an in-house fabricated enclosure under an inert nitrogen atmosphere. 


\subsection{Pseudo-reference electrode measurements}

Macroelectrode cyclic voltammograms were performed in triplicate at a scan rate of $100 \mathrm{mV}$ $\mathrm{s}^{-1}$ using a VSP potentiostat (Bio-Logic) in electrolytes with a total MEEPT/MEEPT ${ }^{+}$ concentration of ca. $10 \mathrm{mM}$ and varying ratios of oxidized and reduced species to approximate different SOCs. Measurements were recorded with $100 \%$ iR correction based on the impedance measured at $200 \mathrm{kHz}$ (Bio-Logic ZIR technique). The working electrode was a Pt disk (BASi, 99.95\%, $3 \mathrm{~mm}$ diameter), the counter electrode was a Pt coil (BASi, 99.95\%), and the pseudoreference electrode was a Pt wire (BASi, 99.95\%, $0.5 \mathrm{~mm}$ diameter). Microelectrode voltammetry measurements were performed in the same electrolytes using a $\mathrm{CHI}-630 \mathrm{E}$ potentiostat $(\mathrm{CH}$ Instruments, Inc.) at a scan rate of $10 \mathrm{mV} \mathrm{s}^{-1}$. The working and counter electrodes were a $10 \mu \mathrm{m}$ diameter gold $(\mathrm{Au})$ disk microelectrode (BASi) and a Pt coil, respectively. The reference electrode was either a Pt wire or a fritted Li foil (Alfa Aesar, 99.9\%) immersed in $1 \mathrm{M}$ lithium tetrafluoroborate (Gotion, >99.9\%) in PC.

\subsection{Flow-through microelectrode sensor}

The flow-through microelectrode sensor (Figure 2) was constructed by integrating commercial electrodes into a 1/4" union cross (Swagelok, 316 stainless steel). A detailed description of the cell construction (Figure S1) as well as a constituent component breakdown (Table S1) can be found in Section S1 of the Supporting Information (SI). In brief, a $10 \mu \mathrm{m}$ diameter Au disk microelectrode (BASi, 99.95\%) was fed through L/S 16 norprene tubing (Masterflex) and sealed into the fitting with stainless steel ferrules. Care was taken to ensure the electrode surface was even with the inner walls of the fitting and placement was confirmed by visual inspection of the flow channel. A Pt wire electrode (CH Instruments, 99.95\%, $0.5 \mathrm{~mm}$ diameter, $1 \mathrm{~cm}$ length), which serves as the pseudo-reference electrode, was placed in the channel opposite the microelectrode. 
The stainless steel fitting itself served as the counter electrode, which was connected to the potentiostat by wrapping a piece of 110 copper wire (McMaster-Carr, 0.040”, 99.9\%) around one side of the fitting. For all experiments in this work, the sensor was oriented vertically such that fluid enters from the bottom and exits from the top, ensuring that electrolyte completely fills the fitting.

For voltammetry experiments, ca. $20 \mathrm{~mL}$ of electrolyte containing $100 \mathrm{mM}$ MEEPT/MEEPT ${ }^{+}$ (ranging from $10-90 \%$ SOC) was continuously sparged with nitrogen (Airgas, 99.999\%) and circulated between a $25 \mathrm{~mL}$ Pyrex ${ }^{\circledR}$ media bottle $\left(\right.$ Corning $\left.^{\circledR}\right)$ and the sensor through L/S 16 norprene tubing using a peristaltic pump (Masterflex L/S series, equipped with an Easy-Load II pump head) operating at variable flow rates. Voltammograms were recorded in triplicate at a scan rate of $10 \mathrm{mV} \mathrm{s}^{-1}$. During ex situ testing, a pulse dampener was integrated upstream of the sensor to smooth out pressure oscillations from the peristaltic pump. Here, a $50 \mathrm{~mL}$ polypropylene syringe, filled with nitrogen, was connected to an additional 1/4" union tee (Swagelok, 316 stainless steel) by a short length (ca. $5 \mathrm{~cm}$ ) of L/S 16 norprene tubing. For L/S 13 and L/S 14 tubing, additional $1 / 4$ " to $1 / 8$ " and $1 / 4$ " to $3 / 16$ " reducing unions (Swagelok, 316 stainless steel), respectively, were connected to the union tee to facilitate flow to the sensor. 

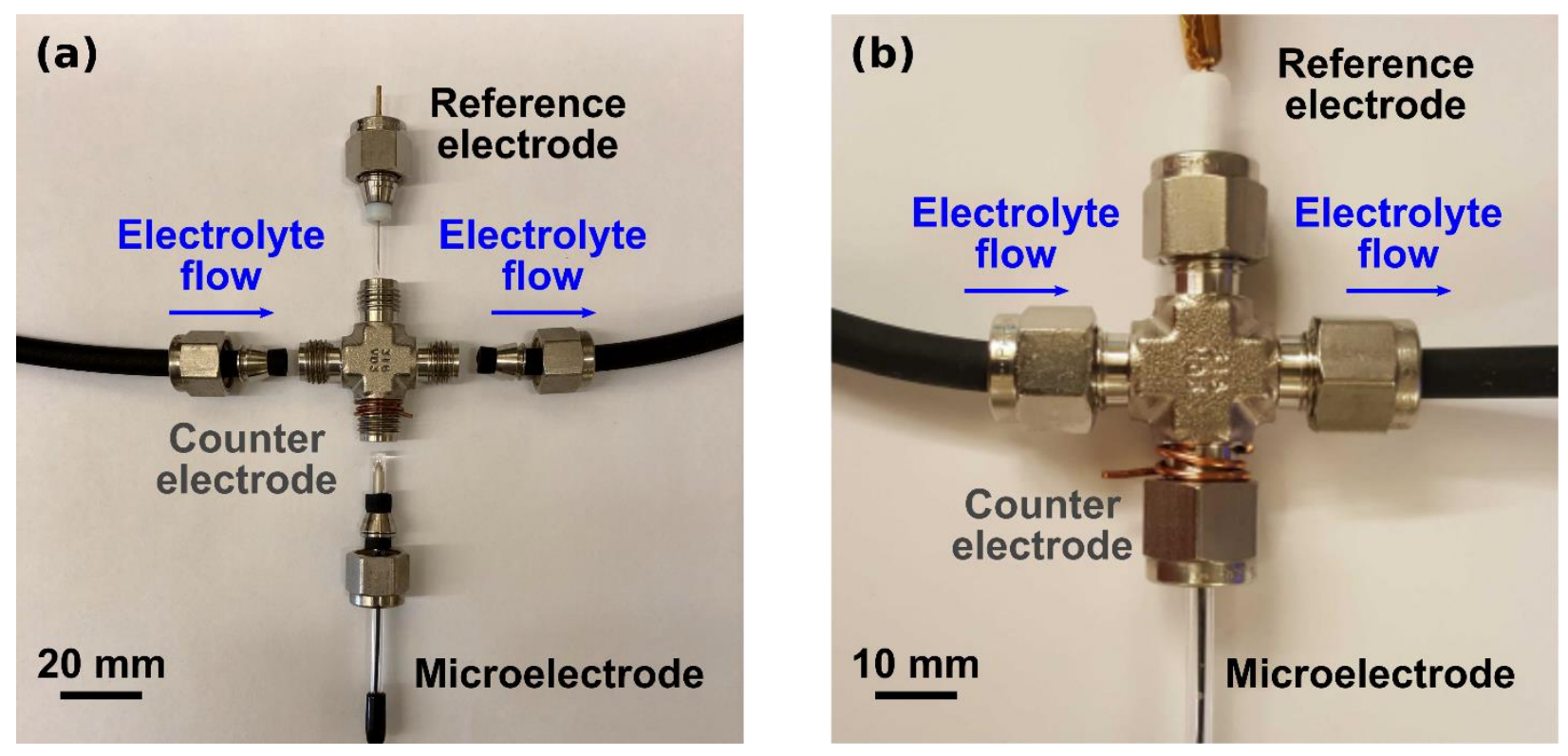

Figure 2. Photographs of the flow-through microelectrode sensor. (a) Exploded view depicting individual components, including the microelectrode, Pt wire pseudo-reference electrode, stainless steel body (counter electrode, connected by a copper wire), and ferrules for sealing the electrodes and tubing. (b) Fully assembled flow-through microelectrode sensor.

\subsection{Operando symmetric cell testing}

Proof-of-concept operando cell cycling measurements were performed on the benchtop in a custom-built, small-volume flow cell. ${ }^{43}$ A symmetric flow cell configuration was used with two identical electrolytes, each $15 \mathrm{~mL}$, composed of $50 \mathrm{mM}$ MEEPT, $50 \mathrm{mM} \mathrm{MEEPT-BF} 4$, and 500 $\mathrm{mM} \mathrm{TEABF} 4$ dissolved in PC. The electrolytes were stored in $10 \mathrm{~mL}$ Savillex jars and delivered to the flow cell using a peristaltic pump through $\mathrm{L} / \mathrm{S} 14$ tubing at $20 \mathrm{~mL} \mathrm{~min}^{-1}$. One side of the cell featured the flow-through microelectrode sensor while the other side featured an identical 1/4" union cross with 1/4" polytetrafluoroethylene (PTFE) plugs in place of the electrodes to balance electrolyte volumes and pressure across the separator. Both components were placed between the pump and the flow cell inlets, and additional $1 / 4$ " to $3 / 16$ " reducing unions were placed at the 
entrance and exit to make the sensor compatible with L/S 14 tubing. The sensor holds ca. $5 \mathrm{~mL}$ and thus accounts for excess electrolyte volume.

In the flow cell, one pristine AvCarb $1071 \mathrm{HCB}$ carbon cloth $(350 \mu \mathrm{m}$ thickness, measured using a Mitutoyo $7300 \mathrm{~S}$ caliper), with an area of $2.55 \mathrm{~cm}^{2}(1.7 \mathrm{~cm} \times 1.5 \mathrm{~cm})$ and compressed by ca. 20\% with PTFE gaskets of suitable thickness, was used as the electrode on each side of the cell. Interdigitated flow fields, milled in-house from Tokai G347B resin-impregnated graphite plates (3.18 mm thick, Tokai Carbon Co.), serve as current collectors and distribute electrolyte throughout the porous electrode. ${ }^{44}$ An untreated Daramic 175 separator $(175 \mu \mathrm{m}$ thickness, measured using the aforementioned caliper) was used to mitigate crossover while maintaining sufficient ionic conductivity. In order to limit ingress of atmospheric oxygen and water into the system during cycling, the cell was kept inside a nitrogen-rich enclosure. Cells were preconditioned by circulating electrolyte through the system for $30 \mathrm{~min}$ to promote component wetting and bubble removal and subsequently cycled using a VSP potentiostat (Bio-Logic) at 10 $\mathrm{mA} \mathrm{cm}{ }^{-2}$ with voltage cutoffs of $\pm 0.5 \mathrm{~V}$.

Active species concentrations were determined during cell cycling by using chronoamperometry to measure the microelectrode steady-state currents. Prior to cycling, a calibration was performed at 50\% SOC by applying constant potentials of $-0.35 \mathrm{~V}$ vs Pt for $10 \mathrm{~s}$ followed by $+0.35 \mathrm{~V}$ vs Pt for $10 \mathrm{~s}$ to determine 1 ) the empirical mass transfer coefficients for oxidation and reduction and 2) the necessary time to reach steady state $(<1 \mathrm{~s})$. Throughout cycling, chronoamperometry was performed every minute, applying the same sequence used for calibration. For both oxidation and reduction, the steady-state current was averaged over the last $9 \mathrm{~s}$ to calculate the final concentration. 


\subsection{Modeling and simulation}

COMSOL Multiphysics ${ }^{\circledR}$ (v. 5.6) was used to perform the three-dimensional (3D) advectiondiffusion simulations. The steady state Laminar Flow and Transport of Diluted Species modules were used to solve the fluid dynamic and mass-transfer equations, respectively, within the simplified 3D microelectrode sensor domain (Figure S2). The fluid dynamic equations, as shown in their generalized form in Eq. (1), were solved alongside the continuity equation (Eq. (2)).

$$
\begin{gathered}
\rho \mathbf{u} \cdot \nabla \mathbf{u}=\nabla \cdot-p \mathbf{I}+\mu \nabla \mathbf{u}+\nabla \mathbf{u}^{T} \\
\rho \nabla \cdot \mathbf{u}=0
\end{gathered}
$$

$\rho\left(\mathrm{kg} \mathrm{m}^{-3}\right)$ is the fluid density, $\mathbf{u}\left(\mathrm{m} \mathrm{s}^{-1}\right)$ is the velocity vector, $p(\mathrm{~Pa})$ is the pressure, $\mathbf{I}$ is the identity tensor, and $\mu$ (Pa s) is the fluid viscosity. Additionally, a symmetry boundary condition (Eq. (3)) was used on the microelectrode side to reduce the computational complexity, with other boundary conditions for the walls, the inlet, and the outlet shown in Eq. (4), (5), and (6), respectively.

$$
\begin{gathered}
\mathbf{u} \cdot \mathbf{n}=0 \\
\mathbf{u}=0 \\
-\int_{\text {inlet }} \rho \mathbf{u} \cdot \mathbf{n} d \mathbf{S}=\mathrm{w}^{2} v \rho \\
-p \mathbf{I}+\mu \nabla \mathbf{u}+\nabla \mathbf{u}^{T}=0
\end{gathered}
$$

$\mathbf{n}$ indicates the normal vector in either the $x, y$, or $z$ spatial dimension, $w(\mathrm{~m})$ is the domain width, and $v\left(\mathrm{~m} \mathrm{~s}^{-1}\right)$ is the scalar velocity. Similarly, the generalized mass transport equation solved in $\mathrm{COMSOL}^{\circledR}$ is shown in Eq. (7).

$$
-D \nabla^{2} c+\mathbf{u} \cdot \nabla c=0
$$


$D\left(\mathrm{~m}^{2} \mathrm{~s}^{-1}\right)$ is the diffusion coefficient and $c\left(\mathrm{~mol} \mathrm{~m}^{-3}\right)$ is the species concentration. Here, the wall with the microelectrode has a symmetry boundary condition (Eq. (8)); the walls and the outlet are subject to a no-flux boundary condition (Eq. (9)); the inlet has a Danckwerts boundary condition (Eq. (10)); the electrode surface invokes a Dirichlet boundary condition, emulating a reactantdepleting event (Eq. (11)).

$$
\begin{gathered}
\mathbf{n} \cdot-D \cdot \nabla c+\mathbf{u} c=0 \\
D \cdot \nabla c=0 \\
\mathbf{n} \cdot-D \cdot \nabla c+\mathbf{u} c=\mathbf{n} \cdot \mathbf{u} c_{0} \\
c_{s}=0
\end{gathered}
$$

$c_{0}$ and $c_{s}\left(\mathrm{~mol} \mathrm{~m}^{-3}\right)$ are the bulk and microelectrode surface concentrations, respectively. The current is then derived from the species flux at the electrode surface (Eq. (12)) with positive current corresponding to oxidation (e.g., oxidation of MEEPT).

$$
I=-n F \int_{S_{e}} \mathbf{n} \cdot\left(\left.D \frac{\partial c}{\partial z}\right|_{z-0}\right) d S
$$

$n$ is the number of electrons transferred (here, $n=1), F\left(96485 \mathrm{C} \mathrm{mol}^{-1}\right)$ is the Faraday constant, and $S_{e}\left(7.85 \times 10^{-11} \mathrm{~m}^{2}\right)$ is the microelectrode surface area.

The justification for the mesh used to solve the fully coupled set of equations is discussed in Section S2 of the SI, whereby the Paradiso solver was used with a relative tolerance of $1 \times 10^{-3}$ and a maximum 100 iterations for the Newton non-linear method. Using the validated mesh (Figure S3 and Table S2), two parameter sweeps were performed, spanning values of $v$ from $0-6 \times 10^{-2}$ $\mathrm{m} \mathrm{s}^{-1}$ in increments of $0.5 \times 10^{-2} \mathrm{~m} \mathrm{~s}^{-1}$ with $c_{0}$ specified at either $1,5,10,25,50,100$, or $200 \mathrm{mM}$. All simulations were completed on a 6-core laptop with 64 GB RAM and an Intel ${ }^{\circledR}$ Core $^{\mathrm{TM}}$ i7$9750 \mathrm{H} \mathrm{CPUs}(2.60 \mathrm{GHz})$ requiring ca. $4.75 \mathrm{~h}$ in total to compute all parametric combinations. 


\section{Results and Discussion}

\subsection{Pseudo-reference electrode validation}

Considering that standard reference electrodes rely on a well-defined redox chemistry isolated from the electrolyte of interest, species in this environment can leak through its separator (typically a porous glass frit), contaminating the RFB electrolyte and accelerating decay processes. Further, contamination of the isolated reference electrode chamber can poison the electrode and destabilize the potential, interfering with electrochemical measurements. ${ }^{30}$ Using a pseudo-reference electrode, we can instead harness the chemistry of the electrolyte itself to yield a more stable potential for voltammetric and chronoamperometric measurements. In this case, the electrode is a Pt wire directly immersed in the electrolyte that measures the potential of the electrochemical processes occurring on the metal surface at equilibrium. While the potential of the reference electrode may shift with the SOC, we are primarily interested in the steady-state currents accessed by the microelectrode, and thus, if conducted properly, the precise value of the potential is inconsequential to the fidelity of the measurement. Here, we compare microelectrode voltammograms under varying SOC conditions for a nonaqueous redox couple, MEEPT/MEEPT ${ }^{+}$, which is stable in both discharged and charged states, to establish the viability of this approach.

To quantify the pseudo-reference electrode potential, we first measure the potential of the Pt wire relative to the formal redox potential of MEEPT/MEEPT ${ }^{+}$using $\mathrm{CV}$ at a disk macroelectrode in deterministically prepared electrolytes with varying SOC (Figure 3a). By calculating the average of the anodic and cathodic $\mathrm{CV}$ peak potentials to estimate the formal redox potential relative to the Pt wire, we can determine the relative potential of the pseudo-reference electrode as a function of electrolyte composition. As expected, the potential shifts in accordance with the Nernst equation, shown by Eq. (13) and (14). 


$$
\begin{aligned}
E & =E^{0}+\frac{R T}{n F} \ln \left(\frac{1-\mathrm{SOC}}{\mathrm{SOC}}\right) \\
\mathrm{SOC} & =\frac{\left[\mathrm{MEEPT}^{+}\right]}{[\mathrm{MEEPT}]+\left[\mathrm{MEEPT}^{+}\right]}
\end{aligned}
$$

Here, $R\left(8.314 \mathrm{~J} \mathrm{~mol}^{-1} \mathrm{~K}^{-1}\right)$ is the universal gas constant and $T(\mathrm{~K})$ is the absolute temperature. Given this robust understanding of the pseudo-reference electrode, we can apply it directly to conventional three-electrode measurements.

Next, we compare the microelectrode responses in the same electrolytes using either the pseudo-reference electrode or a more commonly used, fritted reference electrode $\left(\mathrm{Li}^{2} / \mathrm{Li}^{+}\right)$. With the more traditional reference electrode (Figure 3b), we only observe a vertical shift in the currents due to changing bulk concentrations which give rise to variable steady-state transport rates. ${ }^{37}$ Under quiescent conditions, the plateau currents are related to the bulk concentration and the diffusion coefficient of the reacting species according to Eq. (15).

$$
I= \pm 4 n F r c_{0} D
$$

Here, $r\left(5 \times 10^{-6} \mathrm{~m}\right)$ is the microelectrode radius. Replacing the reference electrode with a pseudoreference electrode introduces horizontal shifts in the curves as a function of electrolyte SOC (Figure 3c), consistent with the anticipated changes in the reference electrode potential. At first, this may seem problematic for a voltammetric measurement; however, our key feature of interest is the steady-state currents, which are independent of the overpotential provided sufficiently positive or negative potentials are applied. We note that some relevant electrolytes may exhibit undesired voltammetric features (e.g., subsequent redox reactions, solvent / electrolyte decomposition), which can lead to inaccuracies at extreme SOCs. In such cases, more common fritted reference electrodes may still be integrated into this cell architecture and periodically cleaned to impose stricter control over the working electrode potential. While standard references 
are more common, those containing the RFB active species at 50\% SOC may hinder contamination due to leaking. ${ }^{30}$
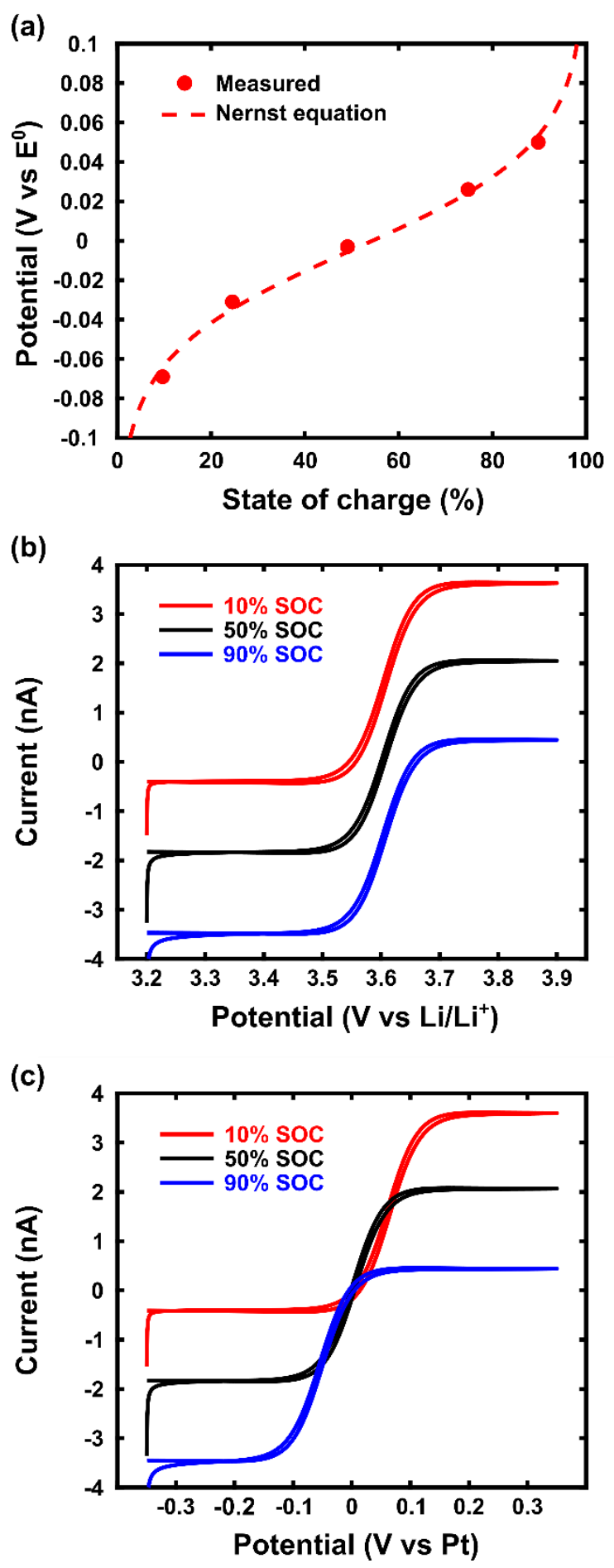
Figure 3. Ex situ reference electrode potential measurements and microelectrode voltammograms measured at varying SOCs in electrolytes containing $10 \mathrm{mM} \mathrm{MEEPT/MEEPT}{ }^{+}$and $500 \mathrm{mM}$ $\mathrm{TEABF}_{4}$ in PC. (a) Pt wire pseudo-reference electrode potential as a function of SOC shown alongside theoretical predictions from the Nernst equation. Measurements were performed in triplicate and the symbols exceed the size of error bars with one standard deviation. (b) Microelectrode voltammograms measured using a fritted $\mathrm{Li} / \mathrm{Li}^{+}$reference electrode compared to (c) a Pt wire pseudo-reference electrode. Voltammograms were conducted on a $10 \mu \mathrm{m} \mathrm{Au}$ microelectrode at $10 \mathrm{mV} \mathrm{s}^{-1}$. Positive currents correspond to MEEPT oxidation and negative currents correspond to $\mathrm{MEEPT}^{+}$reduction.

\subsection{Microelectrodes under flow}

To provide theoretical foundations for the role of advection across the electrode surface, a $\mathrm{COMSOL}^{\circledR}$ model was designed as a simplification of the microelectrode sensor domain. By systematically varying the electrolyte composition and flow rate, this simulation platform provides a means to probe the working principles of the apparatus prior to experimental validation. For context, the linear velocities and electrolyte properties used in this model were chosen to mimic the range of conditions expected in the experimental cell. Average fluid velocities of $0-0.06 \mathrm{~m}$ $\mathrm{s}^{-1}$ correspond approximately to volumetric flow rates of $0-10^{-6} \mathrm{~m}^{3} \mathrm{~s}^{-1}\left(0-70 \mathrm{~mL} \mathrm{~min}^{-1}\right)$ based

on the channel diameter at the inlet and outlet $\left(5 \times 10^{-3} \mathrm{~m}\right)$. The following transport parameters were measured in electrolytes containing $100 \mathrm{mM} \mathrm{MEEPT/MEEPT}{ }^{+}$at $50 \% \mathrm{SOC}$ and $500 \mathrm{mM}$ $\mathrm{TEABF}_{4}$ in PC: $\mu=3.96 \times 10^{-3} \mathrm{~Pa} \mathrm{~s}, \rho=1190 \mathrm{~kg} \mathrm{~m}^{-3}$, and $D=1.7 \times 10^{-10} \mathrm{~m}^{2} \mathrm{~s}^{-1}$ for both the reduced and oxidized species (determined by microelectrode voltammetry and $\mathrm{CV}^{45}$ ). 
The model generates a concentration profile, driven by advection and diffusion to the electrode surface, which allows for the determination of the steady-state current from the species flux. Plotting this current as a function of the electrolyte velocity (Figure 4a), we observe a transition from diffusion-dominated transport at low fluid velocities to advection-dominated transport at high fluid velocities, scaling with the square root of the velocity, which is consistent with canonical models of fluid flow over a flat plate. ${ }^{46}$ The non-linear scaling with respect to flow rate challenges prediction of the steady-state current via simple mathematical relationships and, in practice, the construction of an idealized planar surface with uniformly laminar flow and controlled mass transport is not feasible. However, theoretical predictions of the current as a function of concentration (Figure 4b) show a linear dependence across all flow regimes, suggesting that the current can be predicted from an empirical mass transfer coefficient, $k_{m}\left(\mathrm{~m} \mathrm{~s}^{-1}\right)$ at each flow rate, as indicated in Eq. (16).

$$
I= \pm n F k_{m} c_{0}
$$

Therefore, an ideal system is not a prerequisite to effectively measure concentration, and as long as consistent and stable flow can be maintained over the microelectrode surface, the steady-state current should be directly proportional to the reactant concentrations.
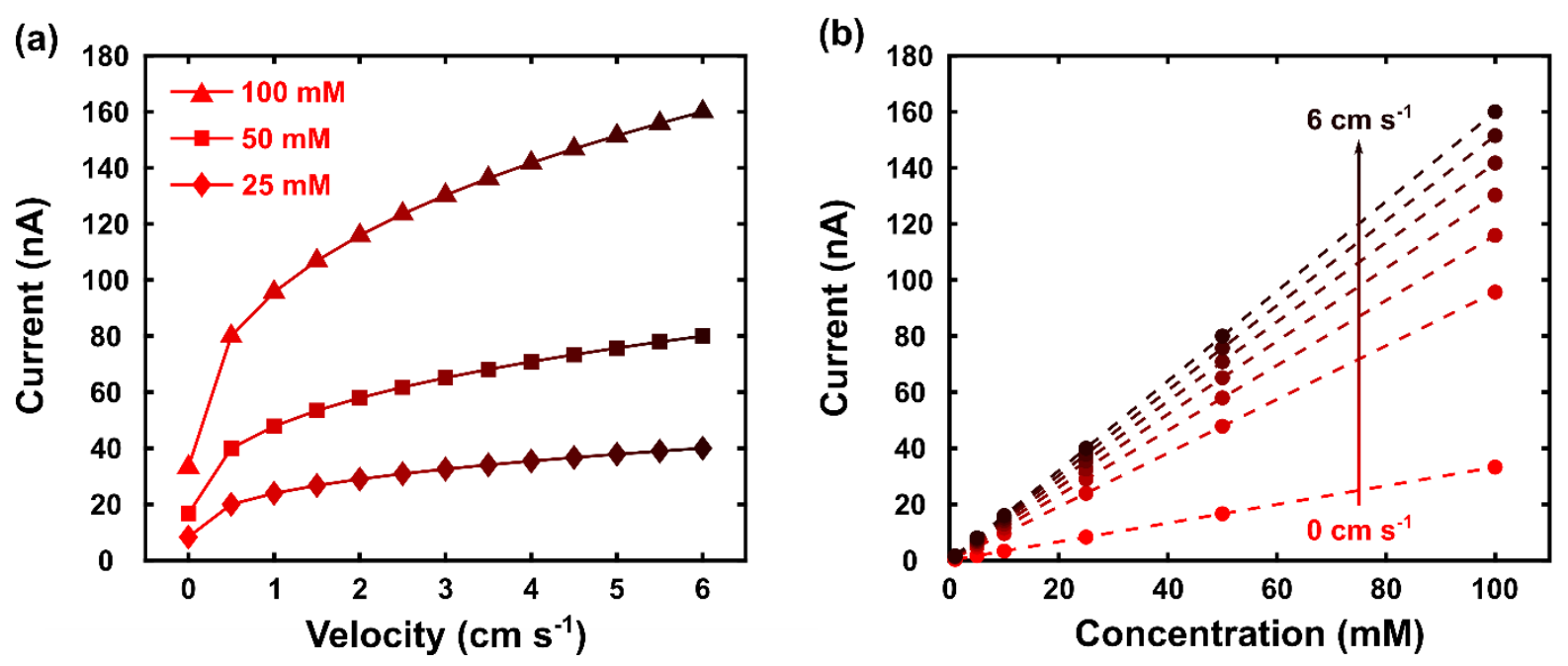
Figure 4. $\mathrm{COMSOL}^{\circledR}$ simulations of the steady-state current to a disk microelectrode shown for a one-electron oxidation under varying electrolyte velocities and active species concentrations. (a) Current as a function of velocity for selected active species concentrations. (b) Linear relationship between current and concentration shown for electrolyte velocities ranging from $0-6 \mathrm{~cm} \mathrm{~s}^{-1}$ in increments of $1 \mathrm{~cm} \mathrm{~s}^{-1}$ and concentrations ranging from $1-100 \mathrm{mM}$. Dashed lines indicate linear fits with all $R^{2}=1$. All simulations were conducted using $D=1.7 \times 10^{-10} \mathrm{~m}^{2} \mathrm{~s}^{-1}, \mu=3.96 \times 10^{-3}$ Pa s, $\rho=1190 \mathrm{~kg} \mathrm{~m}^{-3}$, and $r=5 \times 10^{-6} \mathrm{~m}$ to mimic experimental conditions used in this work.

To confirm these theoretical underpinnings prior to implementation in an operating flow cell with dynamically varying concentrations, we performed ex situ testing using deterministicallyprepared electrolytes. We constructed the sensor (Figure 2) from off-the-shelf components, sealing a $10 \mu \mathrm{m}$ Au microelectrode and a Pt wire pseudo-reference electrode inside of a 1/4" stainless steel union cross, which served as the counter electrode. We then measured

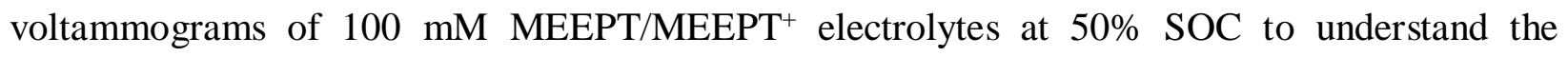
microelectrode response to variable flow rates (Figures $\mathbf{S 4 a}$ and $\mathbf{S 4 b}$ ). Interestingly, the voltammograms display an oscillatory behavior that changes with flow rate, which may at first appear to be random noise due to boundary layer disruption. However, closer inspection of the experimental setup reveals that the oscillations are consistent with the frequency of the peristaltic pump, indicating that the microelectrode captures these subtle changes in flow rate. To confirm that these variations were due to the mode of fluid delivery rather than an artifact of the microelectrode environment, we sought to stabilize the flow by introducing a flow dampener upstream of the sensor (Figure S5) to reduce the oscillations and yield a more consistent measure of the current. 
Repeating the variable flow rate measurements, we find that at high flow rates $\left(>20 \mathrm{~mL} \mathrm{~min}^{-1}\right)$, and thus high rotational frequencies, the smoother flow profile yields a more constant steady-state current, which scales with increasing flow rate (Figure 5a). The relationship between current and electrolyte velocity (Figure S6) qualitatively follows the trends derived from Figure 4, although, as expected, the magnitude of the current differs between the theoretical model and the experimental measurements with and without the pulse dampener. Additionally, decreasing the tubing size used in the peristaltic pump from L/S 16 to L/S 14 and L/S 13 alters the relationship between steady-state current and flow rate (Figures S7 and S8). Considering the irregular channel geometry and pulsatile nature of the flow, these discrepancies are most likely the result of nonuniform velocity distributions throughout the measurement cell, which, in turn, lead to further deviations in transport phenomena from the flat plate contemplated in our model. It is important to reiterate that an idealized flow geometry is not required for high fidelity concentration measurements, and in all instances, the steady-state currents remain stable and are sufficient for this technique. The signal obtained under flow is also notably less sensitive to physical disturbances (e.g., walking by the experimental setup) as compared to microelectrode measurements in quiescent solutions. This suggests that the flow-through sensing approach imposes hydrodynamic conditions that impart greater stability in the local environment, providing measurements which are less susceptible to boundary layer disruptions.

To validate the concentration dependence and thus the working principle behind the sensor, we repeated these measurements at varying active species concentrations similar to those used in Figure $\mathbf{4 b}$. Specifically, the electrolytes contained the same total active species concentration (ca. $100 \mathrm{mM}$ MEEPT/MEEPT ${ }^{+}$) with differing ratios of oxidized and reduced species to approximate SOCs between $10-90 \%$. Using the plateau currents obtained under quiescent conditions, we first 
calibrated the actual concentration of each species using Eq. (15), again taking the diffusion coefficients to be $1.7 \times 10^{-10} \mathrm{~m}^{2} \mathrm{~s}^{-1}$. Figure $5 \mathbf{b}$ shows the resulting plateau currents as a function of the concentrations of MEEPT and $\mathrm{MEEPT}^{+}$with volumetric flow rates ranging from $0-70 \mathrm{~mL}$ $\mathrm{min}^{-1}$ and concentrations ranging from $10-90 \mathrm{mM}$. Although the empirical mass transfer coefficients differ from the model due to differences in the cell geometry and internal fluid dynamics, the linear dependence on the concentration is maintained across this range of SOCs, confirming the theoretical predictions and establishing the promise of this sensor. These measurements also demonstrate high accuracy with close linear fits $\left(R^{2}>0.999\right)$ in all cases; however, the sensitivity and limit of detection will likely depend on the species concentrations, electrolyte flow rates, electrolyte properties, and instrumentation limits used in practice.
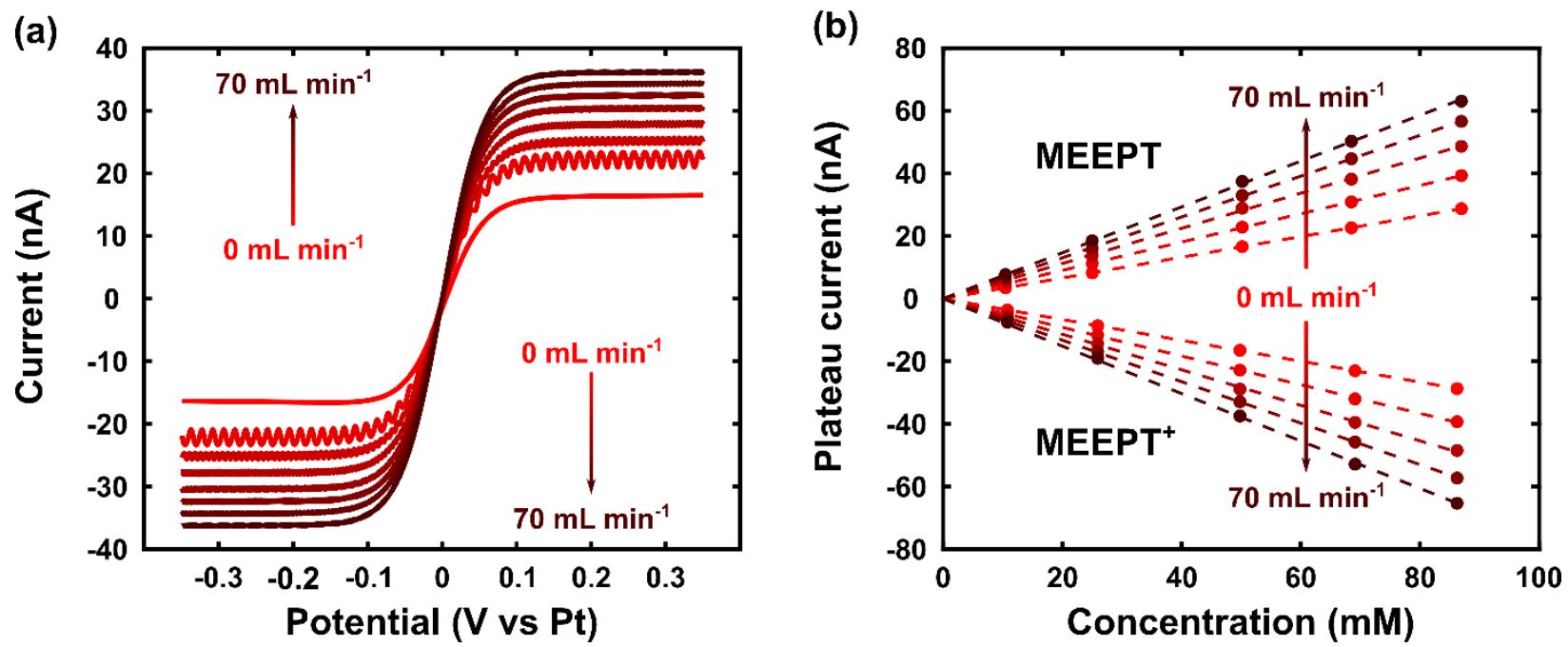

Figure 5. Experimental flow-through microelectrode measurements at variable SOCs and flow rates for electrolytes containing $100 \mathrm{mM} \mathrm{MEEPT/MEEPT}{ }^{+}$and $500 \mathrm{mM} \mathrm{TEABF}_{4}$ in $\mathrm{PC}$ at $\mathrm{SOCs}$ between $10-90 \%$. (a) Microelectrode voltammograms in MEEPT/MEEPT ${ }^{+}(50 \%$ SOC) measured at $10 \mathrm{mV} \mathrm{s}^{-1}$ for flow rates ranging from $0-70 \mathrm{~mL} \mathrm{~min}{ }^{-1}$ in increments of $10 \mathrm{~mL} \mathrm{~min}^{-1}$. (b) Average steady-state currents as a function of MEEPT and MEEPT $^{+}$concentration taken from 
voltammograms measured at $0,10,30,50$, and $70 \mathrm{~mL} \mathrm{~min}^{-1}$ in electrolytes prepared at $10,25,50$, 75, and 90\% SOC. Measurements were performed in triplicate and the symbols exceed the size of error bars with one standard deviation. Dashed lines indicate linear fits with all $R^{2}>0.999$. 


\subsection{Measuring concentrations in a redox flow cell}

Finally, with the sensor performance validated externally, we conducted operando measurements to establish a proof-of-concept for this measurement platform. Specifically, we cycled the same redox couple, MEEPT/MEEPT ${ }^{+}$, in a symmetric flow cell configuration. ${ }^{41,43}$ Both electrolytes were prepared at 50\% SOC with $100 \mathrm{mM}$ total active species concentration and circulated through the cell at $20 \mathrm{~mL} \mathrm{~min}{ }^{-1}$ under galvanostatic conditions at $10 \mathrm{~mA} \mathrm{~cm}{ }^{-2}$ with potential limits of $\pm 0.5 \mathrm{~V}$. The microelectrode sensor was used without the pulse dampener to mitigate pressure imbalances across the separator and placed between the pump outlet and flow cell to continuously sample the inlet concentrations. Although the sensor applies current directly to the electrolyte, because both the working and counter electrodes are present in the same electrolyte, the reactions are anticipated to be equal and opposite, negating any net changes in SOC from the measurement.

Rather than performing a full linear or CV sweep, which require several minutes to collect data at sufficiently low scan rates, we perform chronoamperometry at sufficiently positive or negative applied potentials to ensure only the steady-state currents are captured, requiring ca. $20 \mathrm{~s}$ (Figure S9). Considering the reference electrode potential varies with SOC, it is important to ensure the overpotentials are high enough to achieve mass transfer limiting conditions without encountering additional redox processes (e.g., oxidation of $\mathrm{MEEPT}^{+}$). Based on our validation of the reference electrode potential (Figure 3a), we apply potentials of $\pm 0.35 \mathrm{~V}$ vs Pt. During cycling, these potentials are each held for a total of $10 \mathrm{~s}$, and after achieving steady state $(<1 \mathrm{~s})$, the current is averaged over the last $9 \mathrm{~s}$ to yield a final value. Initially, a calibration is performed using the same procedure and a known electrolyte composition to calculate the empirical mass transfer coefficient via Eq. (16), which is subsequently used to measure concentrations during cell cycling. As 
discussed above, the mass transfer coefficient is a function of the electrolyte flow rate, cell geometry, and tubing size, but as these parameters remain unchanged throughout cycling, this coefficient need only be determined once immediately prior to use. It should also be noted that the approach outlined here assumes a constant viscosity across the system lifetime and across all electrolyte SOCs, as variable electrolyte viscosity can influence the species diffusivity and fluid dynamics which impact the empirical mass transfer coefficient. While such conditions are not anticipated based on our initial validation (Figure 5b), this may be a consideration if more concentrated electrolytes are used, necessitating additional calibrations at different SOCs. ${ }^{43,47,48}$

We initially contemplated two possible architectures for this sensor: 1) a bleed stream, continuously sampling the electrolyte reservoir of the flow cell, and 2) in-line with the cell inlet stream, continuously sampling the electrolyte entering the flow cell. Of the two configurations, we found the in-line measurement to be less disruptive, as the bleed stream displaces significant volumes of electrolyte from the fluidic circuit between the cell and reservoir. While this displacement was incompatible with our current experimental setup given the small electrolyte volumes (ca. $15 \mathrm{~mL}$ per half-cell), it may have greater value in larger embodiments with increased electrolyte volumes.

Figure 6a shows the potentiometric charge/discharge profiles for the flow cell, which are typical of a symmetric cycling experiment, while Figure $6 \mathbf{b}$ shows the corresponding concentration profiles, which align with the variations in cell voltage. As expected, the measured concentrations change linearly with time because galvanostatic operation imposes a constant reaction rate to the electrolyte. Further, the cell exhibited negligible capacity fade with near $100 \%$ coulombic efficiency throughout cycling (Figure S10), which is consistent with the stable species concentrations measured by the sensor as well as with prior literature. ${ }^{41}$ From the applied current, 
we can directly quantify the charge passed over time (i.e., coulomb counting) in each half-cell, and, through Faraday's Law, relate that to the concentrations measured by the sensor (Figure 6b). ${ }^{22}$ While this method is not analytically precise and does not capture additional transient processes such as crossover and decomposition, it can serve as an additional semi-quantitative check of the anticipated sensor performance. Indeed, comparing this approximation with the experimental results shows good agreement, suggesting that the sensor accurately measures changes in concentrations. However, there are minor deviations between the two methods (Figure S11), which we tentatively attribute to a combination of incomplete mixing in the reservoirs, inexact electrolyte volumes, and crossover effects. Taken together, these results represent a successful proof-of-concept demonstration of monitoring active species concentrations within an operating redox flow cell. 
(a)

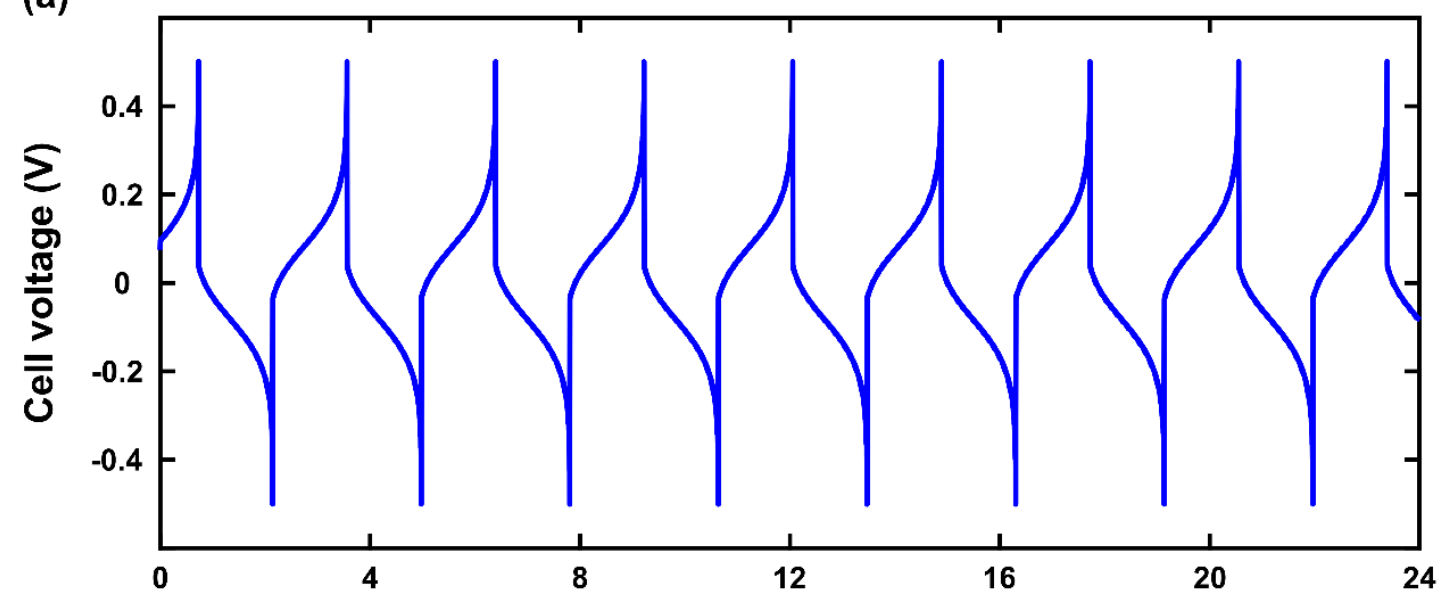

Time (h)

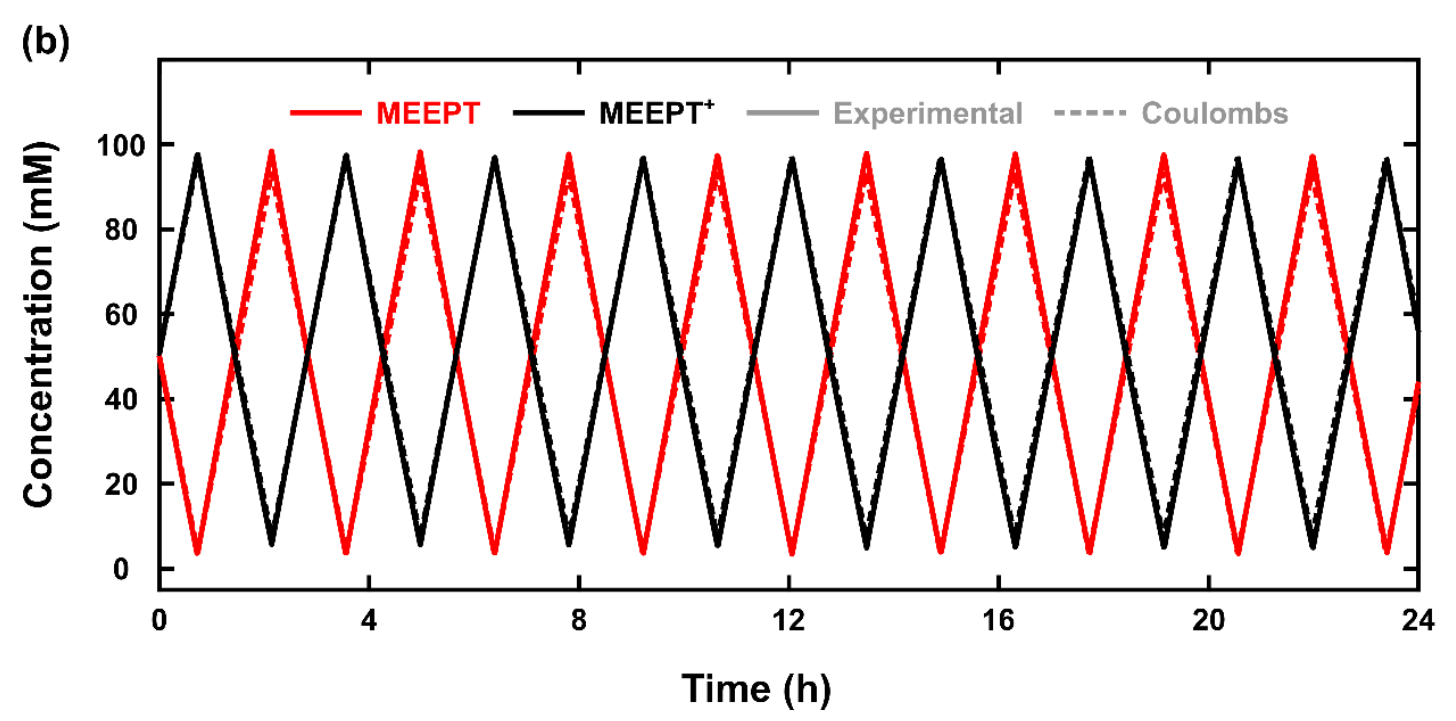

Figure 6. Proof of concept experiment for integration of the microelectrode sensor into a symmetric redox flow cell containing $100 \mathrm{mM} \mathrm{MEEPT} \mathrm{and} \mathrm{MEEPT-BF} 4$, initially at 50\% SOC, flowing at $20 \mathrm{~mL} \mathrm{~min}^{-1}$ and cycled at $10 \mathrm{~mA} \mathrm{~cm}^{-2}$. (a) Cell voltage as a function of time and (b) corresponding species concentrations determined using the flow-through microelectrode sensor. The experimentally measured concentration is compared with concentration predictions derived from coulomb counting. 
To interrogate the stability of the electrode surface over the course of cell cycling, we maintained a control electrolyte, identical to that used for cycling, inside the glovebox. Because the composition and SOC of this electrolyte should remain constant, any changes in the voltammetric signal reflect changes to the microelectrode. Comparing voltammograms before and after cycling (Figure S12a), we observe negligible changes in the measured current, confirming that the Au microelectrode was stable throughout the experiment. However, when we conducted a similar cycling experiment using a Pt microelectrode subjected to the same chronoamperometry conditions, we observed a marked decrease in the voltammetric steady-state currents in the control electrolyte (Figure S12b). Considering that similar decreases were observed for both plateaus and that the signal was recoverable via polishing, this fouling is likely the result of losses in the electrochemically active surface area ${ }^{37,40}$ Further, as we did not observe fouling when the electrode is simply exposed to the electrolyte for extended periods, we posit that this reduction in surface area is a product of the duration and frequency of the potential holds. In this work, the current was measured every minute to elicit the dynamic concentrations during cycling, but applications such as $\mathrm{SOH}$ assessments, species decay monitoring, and crossover detection may demand less frequent measurements. As a result, they may be more resilient to the effects of fouling and thus can more readily integrate this sensing platform. In general, the design and implementation of microelectrode sensing schemes will require careful selection of electrode active species pairs that demonstrate minimal fouling; but where such combinations may not exist, the reliability of the signal can still be reasonably maintained by subjecting the surface to less frequent and shorter polarizations. The signal can also be periodically recovered by either polishing or replacing the fouled electrode. 


\section{Conclusions}

We successfully demonstrate a flow-through, microelectrode-based electrochemical sensor for measuring operando active species concentrations in redox flow cells. The flow cell sensor was assembled from off-the-shelf components obtained from commercial suppliers and investigated through ex situ and operando testing as well as multiphysics simulation. The theoretical and experimental results establish the fundamental underpinnings of sensor operation; namely, under controlled hydrodynamic conditions and constant flow rates, the steady-state currents are linearly dependent on redox species concentrations. Symmetric flow cell cycling provides a proof-ofconcept validation that the sensor is capable of continuously and accurately measuring SOC and $\mathrm{SOH}$ during cell operation. Considering its ease of implementation into existing experimental workflows, the sensor has broad potential utility in research and commercial technologies for monitoring component stability during cell cycling, particularly when quantifying the impact of redox species decomposition and/or crossover. While the device is functional in practice, the sensing mechanism can be further improved by better controlling flow through cell engineering such that steady-state transport may be predicted by power-law models as opposed to empirical internal calibrations.

\section{CRediT authorship contribution statement}

Bertrand J. Neyhouse: Conceptualization, Data curation, Investigation, Methodology, Software, Validation, Visualization, Writing - original draft, Writing - review and editing. Kevin M. Tenny: Data curation, Methodology, Software, Visualization, Writing - original draft, Writing - review and editing. Yet-Ming Chiang: Funding acquisition, Resources. Fikile R. Brushett: 
Conceptualization, Funding acquisition, Project administration, Resources, Supervision, Writing - original draft, Writing - review and editing.

\section{Acknowledgments}

This work was funded by the National Science Foundation (NSF) under Award Number 1805566.

B.J.N and K.M.T gratefully acknowledge the NSF Graduate Research Fellowship Program under Grant Number 1122374. Any opinion, findings, and conclusions or recommendations expressed in this material are those of the authors and do not necessarily reflect the views of the NSF. This work was also partially supported as part of the Joint Center for Energy Storage Research, an Energy Innovation Hub funded by the U.S. Department of Energy, Office of Science, Basic Energy Sciences. The authors also thank Dr. Aman Kaur of the Odom Research Group in the Department of Chemistry at the University of Kentucky for synthesizing the MEEPT-BF 4 used in this study. 


\section{Nomenclature}

\section{Roman symbols}

\begin{tabular}{|c|c|c|}
\hline Symbol & Meaning & Units \\
\hline$c$ & Concentration & $\mathrm{mol} \mathrm{m}^{-3}$ \\
\hline$c_{0}$ & Bulk concentration & $\mathrm{mol} \mathrm{m}^{-3}$ \\
\hline$c_{\mathrm{s}}$ & Concentration at microelectrode surface & $\mathrm{mol} \mathrm{m}^{-3}$ \\
\hline$D$ & Diffusivity & $\mathrm{m}^{2} \mathrm{~s}^{-1}$ \\
\hline$E$ & Electrode potential & V \\
\hline$E^{0}$ & Formal potential & $\mathrm{V}$ \\
\hline$F$ & Faraday constant $\left(96,485 \mathrm{C} \mathrm{mol}^{-1}\right)$ & $\mathrm{C} \mathrm{mol}^{-1}$ \\
\hline$I$ & Current & A \\
\hline $\mathbf{I}$ & Identity matrix & - \\
\hline$k_{m}$ & Mass transfer coefficient & $\mathrm{m} \mathrm{s}^{-1}$ \\
\hline $\mathbf{n}$ & Unit normal vector & - \\
\hline$n$ & Number of electrons transferred & - \\
\hline$p$ & Pressure & $\mathrm{Pa}$ \\
\hline$r$ & Microelectrode radius & $\mathrm{m}$ \\
\hline$R$ & Ideal gas constant $\left(8.314 \mathrm{~J} \mathrm{~mol}^{-1} \mathrm{~K}^{-1}\right)$ & $\mathrm{J} \mathrm{mol}^{-1} \mathrm{~K}^{-1}$ \\
\hline$S_{e}$ & Microelectrode surface & $\mathrm{m}^{2}$ \\
\hline SOC & Electrolyte state of charge & - \\
\hline$T$ & Temperature & $\mathrm{K}$ \\
\hline $\mathbf{u}$ & Velocity vector & $\mathrm{m} \mathrm{s}^{-1}$ \\
\hline$v$ & Scalar velocity & $\mathrm{m} \mathrm{s}^{-1}$ \\
\hline
\end{tabular}




\begin{tabular}{|l|l|l|}
\hline$w$ & Domain width & $\mathrm{m}$ \\
\hline$z$ & Coordinate axis orthogonal to the microelectrode surface & $\mathrm{m}$ \\
\hline
\end{tabular}

\section{Greek symbols}

\begin{tabular}{|c|l|l|}
\hline Symbol & Meaning & Units \\
\hline$\mu$ & Viscosity & Pa s \\
\hline$\rho$ & Density & $\mathrm{kg} \mathrm{m}^{-3}$ \\
\hline
\end{tabular}




\section{References}

(1) Trahey, L.; Brushett, F. R.; Balsara, N. P.; Ceder, G.; Cheng, L.; Chiang, Y.-M.; Hahn, N. T.; Ingram, B. J.; Minteer, S. D.; Moore, J. S.; Mueller, K. T.; Nazar, L. F.; Persson, K. A.; Siegel, D. J.; Xu, K.; Zavadil, K. R.; Srinivasan, V.; Crabtree, G. W. Energy Storage Emerging: A Perspective from the Joint Center for Energy Storage Research. PNAS 2020, 117 (23), 12550-12557. https://doi.org/10.1073/pnas.1821672117.

(2) Albertus, P.; Manser, J. S.; Litzelman, S. Long-Duration Electricity Storage Applications, Economics, and Technologies. Joule 2020, 4 (1), 21-32. https://doi.org/10.1016/j.joule.2019.11.009.

(3) Perry, M. L.; Weber, A. Z. Advanced Redox-Flow Batteries: A Perspective. J. Electrochem. Soc. 2016, 163 (1), A5064-A5067. https://doi.org/10.1149/2.0101601jes.

(4) Li, M.; Rhodes, Z.; Cabrera-Pardo, J. R.; Minteer, S. D. Recent Advancements in Rational Design of Non-Aqueous Organic Redox Flow Batteries. Sustainable Energy Fuels 2020, 4 (9), 4370-4389. https://doi.org/10.1039/D0SE00800A.

(5) Rodby, K. E.; Carney, T. J.; Ashraf Gandomi, Y.; Barton, J. L.; Darling, R. M.; Brushett, F. R. Assessing the Levelized Cost of Vanadium Redox Flow Batteries with Capacity Fade and Rebalancing. Journal of Power Sources 2020, 460, 227958. https://doi.org/10.1016/j.jpowsour.2020.227958.

(6) Rodby, K. E.; Perry, M. L.; Brushett, F. R. Assessing Capacity Loss Remediation Methods for Asymmetric Redox Flow Battery Chemistries Using Levelized Cost of Storage. Journal of Power Sources 2021, 506, 230085. https://doi.org/10.1016/j.jpowsour.2021.230085.

(7) Baran, M. J.; Braten, M. N.; Sahu, S.; Baskin, A.; Meckler, S. M.; Li, L.; Maserati, L.; Carrington, M. E.; Chiang, Y.-M.; Prendergast, D.; Helms, B. A. Design Rules for Membranes from Polymers of Intrinsic Microporosity for Crossover-Free Aqueous Electrochemical Devices. Joule 2019. https://doi.org/10.1016/j.joule.2019.08.025.

(8) Kwabi, D. G.; Ji, Y.; Aziz, M. J. Electrolyte Lifetime in Aqueous Organic Redox Flow Batteries: A Critical Review. Chem. Rev. 2020, 120 (14), 6467-6489. https://doi.org/10.1021/acs.chemrev.9b00599.

(9) Perry, M. L.; Saraidaridis, J. D.; Darling, R. M. Crossover Mitigation Strategies for RedoxFlow Batteries. Current Opinion in Electrochemistry 2020, 21, 311-318. https://doi.org/10.1016/j.coelec.2020.03.024.

(10) Murali, A.; Nirmalchandar, A.; Krishnamoorthy, S.; Hoober-Burkhardt, L.; Yang, B.; Soloveichik, G.; Prakash, G. K. S.; Narayanan, S. R. Understanding and Mitigating Capacity Fade in Aqueous Organic Redox Flow Batteries. J. Electrochem. Soc. 2018, 165 (7), A1193. https://doi.org/10.1149/2.0161807jes.

(11) Nolte, O.; Volodin, I. A.; Stolze, C.; Hager, M. D.; Schubert, U. S. Trust Is Good, Control Is Better: A Review on Monitoring and Characterization Techniques for Flow Battery Electrolytes. Mater. Horiz. 2021. https://doi.org/10.1039/D0MH01632B.

(12) Kaur, A. P.; Holubowitch, N. E.; Ergun, S.; Elliott, C. F.; Odom, S. A. A Highly Soluble Organic Catholyte for Non-Aqueous Redox Flow Batteries. Energy Technology 2015, 3 (5), 476-480. https://doi.org/10.1002/ente.201500020.

(13) Petchsingh, C.; Quill, N.; Joyce, J. T.; Eidhin, D. N.; Oboroceanu, D.; Lenihan, C.; Gao, X.; Lynch, R. P.; Buckley, D. N. Spectroscopic Measurement of State of Charge in Vanadium Flow Batteries with an Analytical Model of VIV-VV Absorbance. J. Electrochem. Soc. 2015, 163 (1), A5068. https://doi.org/10.1149/2.0091601jes. 
(14) Zhao, E. W.; Jónsson, E.; Jethwa, R. B.; Hey, D.; Lyu, D.; Brookfield, A.; Klusener, P. A. A.; Collison, D.; Grey, C. P. Coupled In Situ NMR and EPR Studies Reveal the Electron Transfer Rate and Electrolyte Decomposition in Redox Flow Batteries. J. Am. Chem. Soc. 2021, 143 (4), 1885-1895. https://doi.org/10.1021/jacs.0c10650.

(15) Zhao, E. W.; Liu, T.; Jónsson, E.; Lee, J.; Temprano, I.; Jethwa, R. B.; Wang, A.; Smith, H.; Carretero-González, J.; Song, Q.; Grey, C. P. In Situ NMR Metrology Reveals Reaction Mechanisms in Redox Flow Batteries. Nature 2020, 579 (7798), 224-228. https://doi.org/10.1038/s41586-020-2081-7.

(16) Sevov, C. S.; Hickey, D. P.; Cook, M. E.; Robinson, S. G.; Barnett, S.; Minteer, S. D.; Sigman, M. S.; Sanford, M. S. Physical Organic Approach to Persistent, Cyclable, LowPotential Electrolytes for Flow Battery Applications. J. Am. Chem. Soc. 2017, 139 (8), 2924-2927. https://doi.org/10.1021/jacs.7b00147.

(17) Huang, J.; Pan, B.; Duan, W.; Wei, X.; Assary, R. S.; Su, L.; Brushett, F. R.; Cheng, L.; Liao, C.; Ferrandon, M. S.; Wang, W.; Zhang, Z.; Burrell, A. K.; Curtiss, L. A.; Shkrob, I. A.; Moore, J. S.; Zhang, L. The Lightest Organic Radical Cation for Charge Storage in Redox Flow Batteries. Sci Rep 2016, 6 (1), 1-9. https://doi.org/10.1038/srep32102.

(18) Zhang, J.; Yang, Z.; Shkrob, I. A.; Assary, R. S.; Tung, S. on; Silcox, B.; Duan, W.; Zhang, J.; Su, C. C.; Hu, B.; Pan, B.; Liao, C.; Zhang, Z.; Wang, W.; Curtiss, L. A.; Thompson, L. T.; Wei, X.; Zhang, L. Annulated Dialkoxybenzenes as Catholyte Materials for NonAqueous Redox Flow Batteries: Achieving High Chemical Stability through Bicyclic Substitution. Advanced Energy Materials 2017, $7 \quad$ (21), 1701272. https://doi.org/10.1002/aenm.201701272.

(19) Nolte, O.; Geitner, R.; Hager, M. D.; Schubert, U. S. IR Spectroscopy as a Method for Online Electrolyte State Assessment in RFBs. Advanced Energy Materials n/a (n/a), 2100931. https://doi.org/10.1002/aenm.202100931.

(20) Rudolph, S.; Schröder, U.; Bayanov, I. M.; Blenke, K.; Hage, D. High Resolution State of Charge Monitoring of Vanadium Electrolytes with IR Optical Sensor. Journal of $\begin{array}{llll}\text { Electroanalytical Chemistry } & \text { 2013, } & \text { 694, }\end{array}$ https://doi.org/10.1016/j.jelechem.2013.01.042.

(21) Gandomi, Y. A.; Aaron, D. S.; Houser, J. R.; Daugherty, M. C.; Clement, J. T.; Pezeshki, A. M.; Ertugrul, T. Y.; Moseley, D. P.; Mench, M. M. Critical Review-Experimental Diagnostics and Material Characterization Techniques Used on Redox Flow Batteries. J. Electrochem. Soc. 2018, 165 (5), A970. https://doi.org/10.1149/2.0601805jes.

(22) Ressel, S.; Bill, F.; Holtz, L.; Janshen, N.; Chica, A.; Flower, T.; Weidlich, C.; Struckmann, T. State of Charge Monitoring of Vanadium Redox Flow Batteries Using Half Cell Potentials and Electrolyte Density. Journal of Power Sources 2018, 378, 776-783. https://doi.org/10.1016/j.jpowsour.2018.01.006.

(23) Li, X.; Xiong, J.; Tang, A.; Qin, Y.; Liu, J.; Yan, C. Investigation of the Use of Electrolyte Viscosity for Online State-of-Charge Monitoring Design in Vanadium Redox Flow Battery. Applied Energy 2018, 211, 1050-1059. https://doi.org/10.1016/j.apenergy.2017.12.009.

(24) Quill, N.; Oboroceanu, D.; Buckley, D. N.; Lynch, R. P. Conductivity of Vanadium Flow Battery (VFB) Catholytes: Dependence on Sulfur and Vanadium Concentration and Temperature. ECS Trans. 2017, 80 (10), 3. https://doi.org/10.1149/08010.0003ecst.

(25) Zelger, C.; Süßenbacher, M.; Laskos, A.; Gollas, B. State of Charge Indicators for Alkaline Zinc-Air Redox Flow Batteries. Journal of Power Sources 2019, 424, 76-81. https://doi.org/10.1016/j.jpowsour.2019.03.099. 
(26) Haisch, T.; Ji, H.; Weidlich, C. Monitoring the State of Charge of All-Vanadium Redox Flow Batteries to Identify Crossover of Electrolyte. Electrochimica Acta 2020, 336, 135573. https://doi.org/10.1016/j.electacta.2019.135573.

(27) Watt-Smith, M. J.; Ridley, P.; Wills, R. G. A.; Shah, A. A.; Walsh, F. C. The Importance of Key Operational Variables and Electrolyte Monitoring to the Performance of an All Vanadium Redox Flow Battery. Journal of Chemical Technology \& Biotechnology 2013, 88 (1), 126-138. https://doi.org/10.1002/jctb.3870.

(28) Knehr, K. W.; Kumbur, E. C. Open Circuit Voltage of Vanadium Redox Flow Batteries: Discrepancy between Models and Experiments. Electrochemistry Communications 2011, 13 (4), 342-345. https://doi.org/10.1016/j.elecom.2011.01.020.

(29) Hayer, N.; Kohns, M. Thermodynamically Rigorous Description of the Open Circuit Voltage of Redox Flow Batteries. J. Electrochem. Soc. 2020, 167 (11), 110516. https://doi.org/10.1149/1945-7111/ab9e85.

(30) Stolze, C.; Hager, M. D.; Schubert, U. S. State-of-Charge Monitoring for Redox Flow Batteries: A Symmetric Open-Circuit Cell Approach. Journal of Power Sources 2019, 423, 60-67. https://doi.org/10.1016/j.jpowsour.2019.03.002.

(31) Struckmann, T.; Kuhn, P.; Ressel, S. A Combined in Situ Monitoring Approach for Half Cell State of Charge and State of Health of Vanadium Redox Flow Batteries. Electrochimica Acta 2020, 362, 137174. https://doi.org/10.1016/j.electacta.2020.137174.

(32) Yang, Z.; Darling, R. M.; Perry, M. L. Electrolyte Compositions in a Vanadium Redox Flow Battery Measured with a Reference Cell. J. Electrochem. Soc. 2019, 166 (13), A3045. https://doi.org/10.1149/2.1161913jes.

(33) Alexis Fenton, J.; Brushett, F. Using Voltammetry Augmented with Physics-Based Modeling and Bayesian Hypothesis Testing to Estimate Electrolyte Composition. 2021. https://doi.org/10.33774/chemrxiv-2021-nfp3b-v2.

(34) Mirceski, V.; Komorsky-Lovrić, S.; Lovrić, M. Square-Wave Voltammetry: Theory and Application; Monographs in Electrochemistry; Springer-Verlag, 2007. https://doi.org/10.1007/978-3-540-73740-7.

(35) Gundry, L.; Guo, S.-X.; Kennedy, G.; Keith, J.; Robinson, M.; Gavaghan, D.; Bond, A. M.; Zhang, J. Recent Advances and Future Perspectives for Automated Parameterisation, Bayesian Inference and Machine Learning in Voltammetry. Chem. Commun. 2021, 57 (15), 1855-1870. https://doi.org/10.1039/D0CC07549C.

(36) Kroner, I.; Becker, M.; Turek, T. Monitoring the State of Charge of the Positive Electrolyte in a Vanadium Redox-Flow Battery with a Novel Amperometric Sensor. Batteries 2019, 5 (1), 5. https://doi.org/10.3390/batteries5010005.

(37) Kowalski, J. A.; Fenton Jr., A. M.; Neyhouse, B. J.; Brushett, F. R. A Method for Evaluating Soluble Redox Couple Stability Using Microelectrode Voltammetry. J. Electrochem. Soc. 2020, 167 (16), 160513. https://doi.org/10.1149/1945-7111/abb7e9.

(38) Bard, A. J.; Faulkner, L. R. Electrochemical Methods: Fundamentals and Applications; Wiley, 2000.

(39) Bond, A. M. Past, Present and Future Contributions of Microelectrodes to Analytical Studies Employing Voltammetric Detection. A Review. Analyst 1994, 119 (11), 1R-21R. https://doi.org/10.1039/AN994190001R.

(40) Stolze, C.; Meurer, J. P.; Hager, M. D.; Schubert, U. S. An Amperometric, TemperatureIndependent, and Calibration-Free Method for the Real-Time State-of-Charge Monitoring 
of Redox Flow Battery Electrolytes. Chem. Mater. 2019, 31 (15), 5363-5369. https://doi.org/10.1021/acs.chemmater.9b02376.

(41) Milshtein, J. D.; Kaur, A. P.; Casselman, M. D.; Kowalski, J. A.; Modekrutti, S.; Zhang, P. L.; Attanayake, N. H.; Elliott, C. F.; Parkin, S. R.; Risko, C.; Brushett, F. R.; Odom, S. A. High Current Density, Long Duration Cycling of Soluble Organic Active Species for NonAqueous Redox Flow Batteries. Energy Environ. Sci. 2016, 9 (11), 3531-3543. https://doi.org/10.1039/C6EE02027E.

(42) Kaur, A. P.; Harris, O. C.; Attanayake, N. H.; Liang, Z.; Parkin, S. R.; Tang, M. H.; Odom, S. A. Quantifying Environmental Effects on the Solution and Solid-State Stability of a Phenothiazine Radical Cation. Chem. Mater. 2020, 32 (7), 3007-3017. https://doi.org/10.1021/acs.chemmater.9b05345.

(43) Milshtein, J. D.; Barton, J. L.; Darling, R. M.; Brushett, F. R. 4-Acetamido-2,2,6,6Tetramethylpiperidine-1-Oxyl as a Model Organic Redox Active Compound for Nonaqueous Flow Batteries. Journal of Power Sources 2016, 327, 151-159. https://doi.org/10.1016/j.jpowsour.2016.06.125.

(44) Milshtein, J. D.; Tenny, K. M.; Barton, J. L.; Drake, J.; Darling, R. M.; Brushett, F. R. Quantifying Mass Transfer Rates in Redox Flow Batteries. J. Electrochem. Soc. 2017, 164 (11), E3265-E3275. https://doi.org/10.1149/2.0201711jes.

(45) Compton, R. G.; Banks, C. E. Understanding Voltammetry, 2nd ed. edition.; ICP, 2011.

(46) Deen, W. M. Analysis of Transport Phenomena, 2nd edition.; Oxford University Press, 2011.

(47) Wang, Y. (王怡琳); Kaur, A. P.; Attanayake, N. H.; Yu, Z. (于洲); Suduwella, T. M.; Cheng, L. (程蕾); Odom, S. A.; Ewoldt, R. H. Viscous Flow Properties and Hydrodynamic Diameter of Phenothiazine-Based Redox-Active Molecules in Different Supporting Salt Environments. Physics of Fluids 2020, 32 (8), 083108. https://doi.org/10.1063/5.0010168.

(48) Xu, Q.; Zhao, T. S.; Zhang, C. Effects of SOC-Dependent Electrolyte Viscosity on Performance of Vanadium Redox Flow Batteries. Applied Energy 2014, 130, 139-147. https://doi.org/10.1016/j.apenergy.2014.05.034. 